\title{
Bradycardia in Maxillofacial Surgery
}

\author{
Krittika Aggarwal ${ }^{1}$ Veerendra Prasad ${ }^{1} \quad$ A. K. Singh ${ }^{1}$ \\ ${ }^{1}$ Department of Plastic Surgery, King George Medical College, \\ Lucknow, Uttar Pradesh, India
}

Indian J Plast Surg 2020;53:166-168

A 20-year-old male had presented with median cleft lip, maxillary hypoplasia Class-II and mandibular prognathism.

He had history of cleft lip repair at 6 years of age and Le Fort I osteotomy, intraoral distractor application with reduction genioplasty in October 2013. He had mandibular prognathism (preoperative photographs are seen in - Fig. $\mathbf{1}$ ). On assessment, the followings are observed: (1) mesoprosopic face, (2) a 2-mm overbite, and (3) a 4-mm overjet ( - Fig. 2 shows lateral and anteroposterior cephalograph).

The patient was planned for Le Fort I osteotomy with rigid external distractor device insertion. The horizontal advancement planned was $7 \mathrm{~mm}$, during the procedure on attempting maxillary mobilization, it was noted that the patient had transient bradycardia up to $40 / \mathrm{min}$. This happened as many mobilization was attempted for several times (thrice). It reverted spontaneously, as soon as
Address for correspondence Krittika Aggarwal, MS, Department of Plastic Surgery, King George Medical College, Lucknow, Uttar Pradesh, 226003, India (e-mail: krittika.agga@gmail.com).

mobilization was stopped. After some time it settled. No other complications were noted. The procedure was completed uneventfully by doing slow and gradual mobilization.

During past 15 years (23 osteotomies), this was encountered for the first time. On reviewing the literature, it was noted that this is a known phenomenon similar to oculocardiac reflex. ${ }^{1-4}$ Lang et $\mathrm{al}^{1}{ }^{1}$ in 1991, reported three adults who had profound bradycardia on mandibular or maxillary manipulation.

Campbell et al, ${ }^{2}$ in 1994 , reported a similar case. It has been postulated that since trigeminal nerve carries the parasympathetic supply, any procedure stimulating the nerve can cause vagal stimulation. Some authors have also suggested to change the name to trigeminocardiac reflex. ${ }^{1,3,4}$ It is a phenomenon which can occur in any patient undergoing maxillary or mandibular manipulation. There are no predisposing factors documented.
DOI https://doi.org/

10.1055/s-0040-1709918

ISSN 0970-0358.
License terms

() (1) $\Theta \circledast$ 

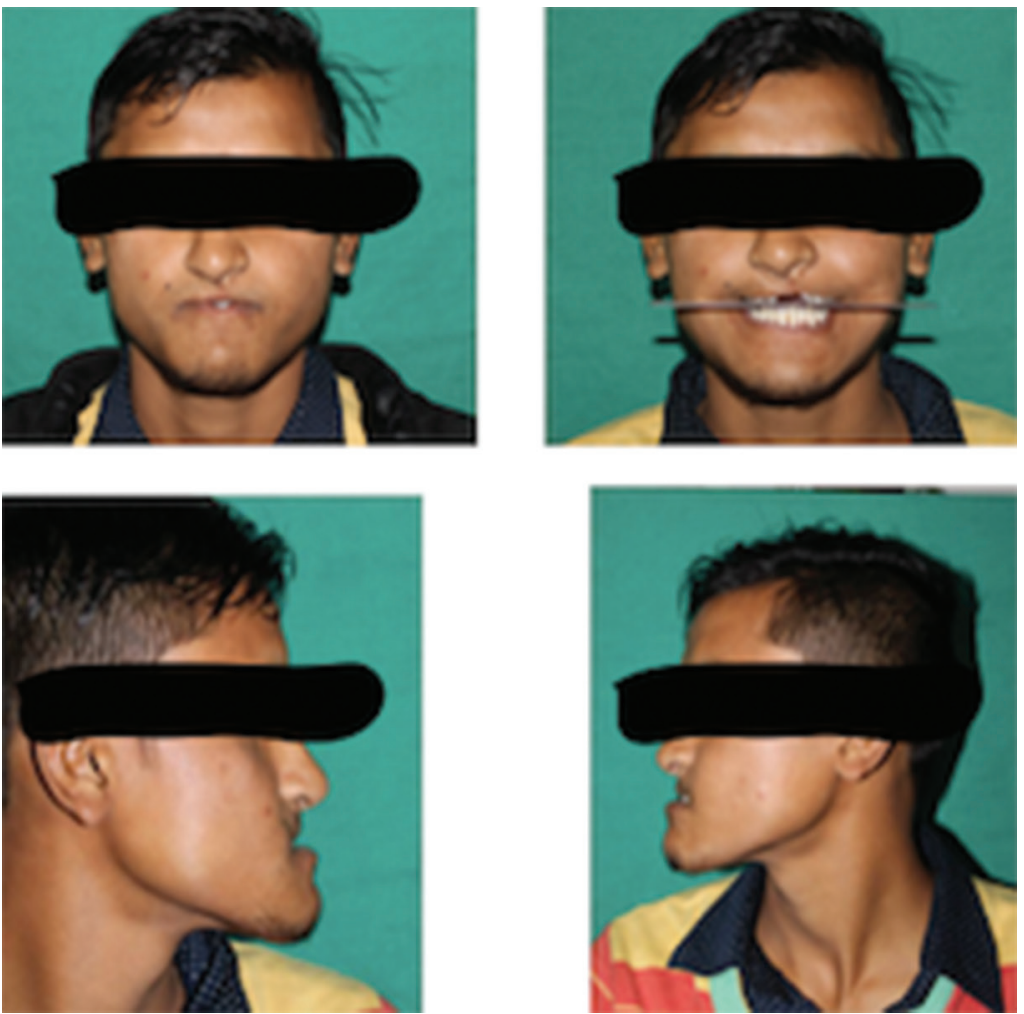

Fig. 1 Preoperative photographs.
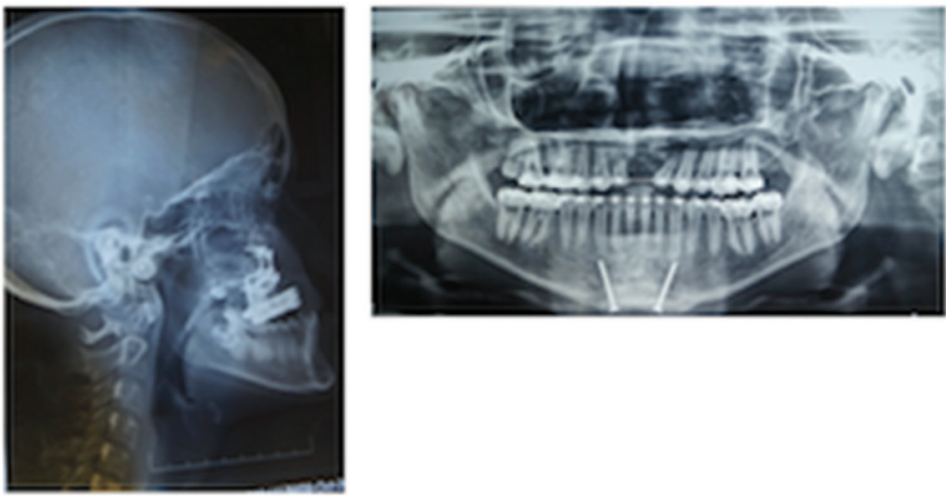

Fig. 2 Lateral and anteroposterior cephalograph.

The purpose is to highlight a hitherto rare occurrence during maxillofacial surgery which may have a bearing on patient.

\section{Conflicting Interest}

None declared.

\section{References}

1 Lang S, Lanigan DT, van der Wal M. Trigeminocardiac reflexes: maxillary and mandibular variants of the oculocardiac reflex. Can J Anaesth 1991;38(6):757-760
2 Campbell R, Rodrigo D, Cheung L. Asystole and bradycardia during maxillofacial surgery. Anesth Prog 1994;41(1):13-16

3 Arasho B, Sandu N, Spiriev T, Prabhakar H, Schaller B. Management of the trigeminocardiac reflex: facts and own experience. Neurol India 2009;57(4):375-380

4 Bhargava D, Thomas S, Chakravorty N, Dutt A. Trigeminocardiac reflex: a reappraisal with relevance to maxillofacial surgery. J Maxillofac Oral Surg 2014;13(4):373-377 
